\title{
А.С. Князьков
}

\section{СОУЧАСТИЕ В НЕЗАКОННОМ СБЫТЕ НАРКОТИЧЕСКИХ СРЕДСТВ И ИХ АНАЛОГОВ, СОВЕРШАЕМОМ ПУТЕМ ИСПОЛЬЗОВАНИЯ ЭЛЕКТРОННЫХ И ИНФОРМАЦИОННО- ТЕЛЕКОММУНИКАЦИОННЫХ СЕТЕЙ}

\begin{abstract}
Рассматриваются проблемь соучастия применительно к такому виду преступной деятельности, как незаконный сбыт наркотических средств и их аналогов относительно новым для уголовной практики способом, состоящим в использовании электронных и информачионно-телекоммуникационных сетей (включая сеть Интернет). Раскрываются признаки устойчивости организованной группы, совершающей незаконный сбыт наркотических средств и их аналогов отмеченным способом. Дается оценка мнения о необходимости распространения модели соучастия на случаи совершения неосторожных преступлений. Формулируется предложение по внесению изменения в УК РФ, направленного на профилактику перерастания организованной группы в преступное сообщество.

Ключевые слова: незаконный сбыт наркотических средств, преступное использование электронных и информационно-телекоммуникационных сетей, соучастие, организованная группа, преступное сообщество.
\end{abstract}

Целью настоящей работы является рассмотрение отдельных аспектов соучастия применительно к преступной деятельности лиц, осуществляющих незаконный сбыт наркотических средств и их аналогов путем использования электронных либо информационно-телекоммуникационных сетей, а также судебной практики по данной категории дел, совершенных в соучастии. Одной из задач исследования явилось рассмотрение соучастия в форме организованной группы, поскольку характер незаконного сбыта указанным способом предполагает существование устойчивых связей между членами группы, выполняющими различные по характеру преступные действия.

Для достижения названной цели использовались системно-структурный, системно-функциональный, формально-юридический, сравнительно-правовой, социологический методы.

В настоящий момент сохраняется устойчивая тенденция к расширению масштабов незаконного сбыта наркотических средств путем использования электронных и информационно-телекоммуникационных сетей (включая сеть Интернет). Такой способ сбыта предполагает существование нескольких лиц, действующих в соучастии, что обусловливает возрастание общественной опасности данного деяния. Она проявляется в возможности снабжения наркотическими средствами и их аналогами значительного числа лиц, незаконно их потребляющих, в сравнительно короткое время, при меньшем риске оказаться быть изобличенным в совершении преступления. Так, 
например, одна из организованных групп, осуществляющих свою преступную деятельность на территории г. Барнаула, в течение дня делала до 250 так называемых «закладок», в каждую из которых помещалось от 0,3 до 3 г наркотиков. Такое положение целиком подтверждает вывод о том, что неофициальное число лиц, допускающих немедицинское потребление наркотических средств и их аналогов в регионах Сибирского федерального округа, исчисляется миллионами [1. С. 38]. Усложнение способов сбыта наркотических средств и их аналогов делает весьма актуальными вопросы соучастия, их форм и видов, содержания преступной деятельности того или иного соучастника.

Неоднозначность подходов в понимании соучастия определено существованием двух теорий соучастия: акцессорной теории соучастия, базирующейся на том, что преступная деятельность организатора, подстрекателя и пособника имеет не самостоятельное, а лишь подчиненное значение по отношению к преступной деятельности исполнителя, и теория самостоятельной ответственности соучастников, получающая выражение в том, что основание уголовной ответственности каждого из соучастников носит самостоятельный характер. Действующее законодательство, исходя из объективных требований практики, предоставляет аргументы сторонникам как одной, так и другой концепции. Это получает отображение в многообразии понимания соучастия: оно трактуется, например, как «...сговор на совершение особо тяжких преступлений, а равно совместное участие двух или более лиц в совершении умышленного преступления» [2. С. 199200], как связь между деяниями виновных, способ их взаимодействия, показывающие, в результате каких деяний соучастников совершается преступление либо осуществляется преступная деятельность [3. С. 255].

Наибольшее распространение получил подход, сторонники которого в вопросах выделения форм соучастия предлагают одновременно оперировать как объективными, так и субъективными критериями. Так, А.В. Шеслер на основе объективных признаков совместности различает соисполнительство (простое соучастие) и соучастие с юридическим разделением ролей (соучастие в узком смысле), имеющее сложный характер. С учетом субъективных признаков соучастников он говорит о двух формах соучастия: соучастии без предварительного сговора и соучастии с предварительным сговором. Затем названный автор предлагает выделять в отношении соучастия с предварительным сговором три вида (формы) соучастия, кладя в основу своей классификации степень согласованности соучастников; такими видами (формами) являются предварительный сговор в простой форме, организованная группа и преступное сообщество [4. С. 23-24]. Такое структурирование целиком соответствует существующим в уголовноправовой науке определениям формы соучастия как «...совокупности объективных и субъективных признаков соучастия, характеризующих совместность деяний соучастников, отражая степень согласованности их действий при подготовке или при совершении преступления и степень общественной опасности самого преступления (преступлений)» [5. С. 8]. 
Поскольку в отечественном законодательстве речь идет о группах, в том числе о преступном сообществе как структурированной группе, для целей выяснения соотношения (сопряжения) понятий «соучастие» и «группа», на наш взгляд, нужно исходить из высказанного Л.М. Прозументовым положения о том, что что любое преступление, совершенное в соучастии, является совершенным группой лиц, однако уточняется, что понятие «преступная группа» может совпадать по своему объему с понятием «соучастие», а может и не совпадать [6. С. 43]. Понятие группы, замечает он, вводится в уголовно-правовую науку и уголовное законодательство для того, чтобы определить и ограничить круг конкретных лиц, принимавших участие в совместном совершении конкретного преступления, т.е. соучастников совместной преступной деятельности. При этом лица, совместно совершившие преступление, выступают через группу как ее участники и одновременно соучастники преступной группы; это помогает определить степень участия каждого члена группы в совершении конкретного преступления, а значит - определить меру участия, меру вовлеченности в совместную преступную деятельность [Там же. С. 45].

Как отмечается, объединение усилий соучастников преступления может осуществляться в двух формах: во-первых, в форме простого объединения их усилий для достижения преступного результата; во-вторых, в форме сложного объединения усилий соучастников, когда каждый из них выполняет различные по характеру действия, обусловливающие действия других соучастников [7. С. 5]. Уголовная ответственность соучастников, подчеркивают отдельные ученые, зависит не только от характера и степени их фактического участия в том или ином преступлении, но и от формы совместной преступной деятельности, поскольку определенные формы соучастия выступают квалифицирующими признаками некоторых составов преступлений. Кроме того, совершение преступления в составе группы лиц, группы лиц по предварительному сговору, организованной группы или преступного сообщества (преступной организации) является, в соответствии со ст. 63 УК РФ, обстоятельством, отягчающим наказание. Наконец, организованная группа и преступное сообщество предопределяют особые основания и пределы уголовной ответственности их соучастников, в частности их организаторов, т.е. лиц, создавших преступную группу или руководивших ею [6. С. 155].

Определенную сложность имеет вопрос о структуре организованной группы, получающей свое отражение в преступной деятельности отдельных его участников. Устойчивость (постоянность) такой группы, как отмечают отдельные авторы, проявляется в системе признаков: относительно стабильный состав участников; длительный или интенсивный период преступной деятельности, который характеризует активность как каждого отдельного участника группы, так и группы в целом; реально существующая структурная (организационная) определенность группы с закреплением ролей ее участников. Соответственно, называются основные предпосылки устойчивости организованной группы, такие как интенсивность деятельно- 
сти преступной группы, удовлетворение через иерархию личного интереса каждого члена группы, наличие психологической защищенности каждого члена группы [6. С. 96].

Вот как, например, в обвинительном заключении по уголовному делу № 421142 о незаконном сбыте наркотических средств путем использования электронных и информационно-телекоммуникационных сетей, рассмотренному Бийским городским судом, доказывается совершение преступлений именно организованной группой. Организованная группа, созданная неустановленными лицами совместно с Мал-ным., в состав которой наряду с ними вошли Ша-лов и По-да, характеризовалась наличием руководителей, которыми являлись неустановленные лица и Мал-нин, а также следующими основными признаками: устойчивостью преступной группы, основанной на постоянстве состава группы, неоднократности совершения преступных действий членами группы в течение длительного периода времени; сплоченностью участников на основе общих преступных замыслов; постоянством методов преступной деятельности, которые гарантировали успешность совершения преступлений по единому, заранее разработанному алгоритму; планированием и подготовкой совершения преступления; распределением ролей и обязанностей между членами преступной группы при подготовке к совершению преступных действий и осуществлении преступного умысла; координацией и взаимосвязанностью действий при непосредственном совершении преступных действий; существованием членов организованной группы на денежные средства, добытые преступным путем; соблюдением правил конспирации и безопасности деятельности преступной группы; поддержанием в группе жесткой дисциплины, предусматривающей применение в отношении некоторых участников группы за ее нарушения насилия. Необходимо сказать, что Мал-нин, ранее многократно приобретавший наркотики для целей личного потребления у неизвестных ему лиц путем переписки с использованием программы Skype, вступил с ними в преступный сговор, направленный на постоянное, в течение длительного времени, совместное совершение особо тяжких преступлений - незаконные приобретение, хранение, перевозка в целях сбыта и сбыт посредством электронных и информационно-телекоммуникационных сетей (включая сеть Интернет) наркотических средств на территории Алтайского края и Новосибирской области. После создания в системе (программе) Skype профиля «Пионер Володя Бийск» с определенным логином он был объявлен неустановленными лицами их представителем на территории Алтайского края; в дальнейшем Мал-нин вовлек в организованную группу Ша-лова и По-ду.

Преступная роль неустановленных руководителей организованной группы, занимавших в иерархии преступной группы наивысшее положение, реализовывалась путем совершения следующих действий:

- осуществление общего руководства и координации деятельности преступной группы, в том числе используя средства электронных и информационно-телекоммуникационных сетей; 
- планирование деятельности преступной группы, осуществление подготовки к совершению преступлений и их сокрытию, в том числе подыскивание источников оптового приобретения наркотических средств и их аналогов;

- незаконные приобретение, перевозка и хранение в целях сбыта оптовых партий наркотических средств и их аналогов, в том числе химических препаратов, на момент приобретения не запрещенных законодательством на территории Российской Федерации;

- организация незаконного сбыта наркотических средств и их аналогов бесконтактным способом, в том числе передача участникам преступной группы с целью последующего незаконного сбыта оптовых партий наркотических средств и их аналогов;

- обучение участников организованной им группы незаконному сбыту наркотических средств и их аналогов бесконтактным способом;

- открытие посредством использования технических средств вычислительной техники и информационно-телекоммуникационных сетей (включая сеть Интернет) виртуальных счетов платежной системы ООО НКО «Яндекс.Деньги», на которые другие участники организованной группы, в том числе Мал-нин, должны были переводить вырученные преступным путем денежные средства за ранее полученные под реализацию оптовые партии наркотических средств и их аналогов;

- осуществление незаконного сбыта наркотических средств и их аналогов путем получения денежных средств и последующего сообщения покупателям места нахождения наркотического средства (их аналога) - «закладки»;

- контроль поступления денежных средств, полученных от незаконного сбыта наркотических средств и их аналогов, на виртуальные счета платежной системы ООО НКО «Яндекс.Деньги»;

- ведение учета доходов, полученных организованной группой, определение порядка их использования, в том числе распределение денежных средств между участниками организованной группы;

- принятие мер к расширению территории незаконного распространения наркотических средств и их аналогов отмеченным способом как в Алтайском крае, так и в близлежащих субъектах Российской Федерации, а также вовлечение в состав организованной группы новых участников;

- осуществление взаимопомощи участниками организованной группы, в том числе и материального характера;

- разбирательство по жалобам со стороны приобретателей наркотиков по фактам необнаружения в указанных местах оплаченных наркотических средств и их аналогов.

Мал-нин в созданной и возглавляемой им совместно с неустановленными лицами преступной группе под общим руководством последних должен был:

- поддерживать связь с неустановленными создателями и руководителями группы, получать от них указания, обмениваться информацией, необходимой для осуществления преступной деятельности, отчитываться 
перед ними о ее результатах, сообщать о преступных планах, в том числе используя электронные и информационно-телекоммуникационные сети;

- осуществлять руководство и координацию преступной деятельности вовлеченных им участников преступной группы Ша-лова и По-ды, в том числе используя электронные и информационно-телекоммуникационные сети;

- планировать деятельность преступной группы для реализации общей преступной цели, осуществлять подготовку к совершению преступлений и их сокрытию;

- получать, перевозить, незаконно хранить для дальнейшего незаконного сбыта оптовые партии наркотических средств и их аналогов;

- с разрешения неустановленных лиц подыскивать другие источники приобретения оптовых партий наркотических средств и их аналогов, приобретать их с целью последующей реализации;

- организовывать незаконный сбыт наркотических средств и их аналогов, передавать участникам преступной группы Ша-лову и По-да наркотические средства и их аналоги с целью последующего их незаконного сбыта;

- обучать участников организованной им группы незаконному сбыту наркотических средств и их аналогов путем использования электронных и информационно-телекоммуникационных сетей;

- открывать посредством использования электронных и информационно-телекоммуникационных сетей виртуальные счета платежной системы «Яндекс.Деньги», лицевые счета платежной системы Visa QIWI Wallet, a также использовать их и уже открытые и находящиеся в пользовании лицевые счета платежной системы Visa QIWI Wallet в своей преступной деятельности для получения от покупателей денежных средств за приобретаемые наркотические средства и их аналоги;

- заниматься приготовлением из полученных оптовых партий наркотических средств и их аналогов путем их смешивания с веществами растительного происхождения, не являющимися наркотическими средствами и их аналогами, для последующей реализации в розницу курительных смесей - «спайсов», а также расфасовывать полученные или приобретенные оптовые партии наркотических средств и их аналогов на разовые дозы, перевозить их и оставлять в различных местах для передачи приобретателям;

- сообщать о местах оставления для приобретателей наркотических средств и их аналогов, их маскировке участнику организованной группы, выполняющему роль «оператора» в бесконтактном сбыте наркотических средств и их аналогов, а также неустановленным создателям и руководителям преступной группы, для их последующего незаконного сбыта; при необходимости выполнять в организованной группе роль «оператора»;

- осуществлять незаконный сбыт наркотических средств и их аналогов при личных встречах с покупателями;

- контролировать поступление денежных средств, полученных от незаконного сбыта наркотических средств и их аналогов, на лицевые счета платежной системы Visa QIWI Wallet; осуществлять переводы поступивших денежных средств с целью сокрытия и вывода денежных средств 
с виртуальных счетов на счета банковских карт с последующим их обналичиваем с помощью терминалов, а также другими способами;

- вести учет и распределение доходов, полученных организованной группой, определять порядок их использования и распределения между участниками организованной группы;

- переводить часть вырученных преступным путем денежных средств за ранее полученные под реализацию оптовые партии наркотических средств и их аналогов на виртуальные счета в системе «Яндекс.Деньги» неустановленным создателям и руководителям преступной группы;

- расширять область незаконного сбыта наркотических средств и их аналогов на территории как Алтайского края, так и близлежащих субъектов Российской Федерации, а также вовлекать в состав организованной группы новых участников;

- осуществлять необходимую для выполнения целей и задач преступной деятельности материальную помощь участникам организованной им группы;

- проводить разбирательства по жалобам со стороны приобретателей наркотиков по фактам необнаружения в указанных им местах оплаченных наркотических средств и их аналогов.

Как видно, организационная роль Мал-нина во многом повторяла роль неустановленных лиц, создавших и руководивших преступной группой.

Преступная роль Ша-лова в основном состояла в производстве так называемых «закладок», а По-ды - в выполнении действий «оператора» лица, указывающего места «закладок» приобретателям наркотических средств и их аналогов путем использования информационно-телекоммуникационных сетей посредством мобильных телефонов, а также с помощью телефонных переговоров и SMS-сообщений.

Аналогичные преступные роли выполняют те или иные члены преступного сообщества, например члены преступного сообщества, созданного Рег-ом, которое организационно оформилось из первоначально созданной им организованной группы.

Для сравнения: в группе лиц по предварительному сговору, осуществляющей незаконный сбыт наркотических средств и их аналогов рассматриваемым способом, ее участники выполняли одинаковые, причем немногочисленные, действия по незаконному хранению наркотиков, оборудованию мест для их закладки, незаконному сбыту наркотиков и получению денег: отличие состояло лишь в том, что один из них незаконно приобретал крупные партии наркотических средств для их дальнейшей расфасовки и реализации.

Именно сущностная характеристика устойчивости организованной группы позволяет отграничить эту форму соучастия от группы лиц, действующих по предварительному сговору, и в этой связи представляется спорным мнение о необходимости исключить из ч. 3. ст. 35 УК РФ характеристику устойчивости организованной группы [8. С. 7]. Также не способствует совершенствованию уголовного законодательства и практике 
предложение различать активных и пассивных соучастников, лиц с первостепенной и второстепенной ролями в преступлении [9. С. 9], в силу многозначности каждого из указанных определений и наличия в числе обстоятельств, отягчающих уголовное наказание, более конкретного обстоятельства, а именно особо активной роли в совершении преступления.

В изученной нами практике можно видеть два принципиальных момента, касающихся порядка появления организованной группы (части организованной группы) для целей незаконного сбыта наркотических средств рассматриваемым способом, в которой соучастники известны друг другу.

1. Инициирование лицом действий по вступлению в уже действующую организованную группу в качестве своеобразного соорганизатора, создающего затем путем вовлечения в преступную деятельность новых участников отдельную организованную группу под контролем вышестоящих организаторов (руководителей). При этом можно видеть такие организационные действия анонимного организатора, как «допуск» к незаконному сбыту наркотических средств рассматриваемым способом лиц, причем обладающих определенными качествами, например умением водить автомашину, хорошим физическим здоровьем, предполагающим воздержание от приема наркотиков.

2. Самостоятельные действия лица либо лиц, договорившихся о создании организованной группы. Здесь организованная группа, сохраняя преступную организационную самостоятельность, сама отыскивает источники получения наркотических средств для их дальнейшего сбыта. При этом чаще всего вовлечение в незаконный сбыт наркотических средств так называемых «писарей» и «курьеров» происходит из числа друзей, родственников, членов семьи организатора, а наркотическая зависимость вовлекаемых в преступную деятельность лиц не является препятствием для вступления их в организованную группу, более того, нередко служит средством такого вовлечения.

Неоднозначно в судебной практике по делам о незаконном сбыте наркотических средств путем использования электронных и информационнотелекоммуникационных сетей решается вопрос о квалификации действий лица, направленных на создание организованной группы или преступного сообщества. Так, например, инициировавшая объединение в организованную группу с неизвестным лицом Акс-ва предложила своей знакомой Кирвой войти в состав участников и непосредственных исполнителей преступлений организованной неустановленными лицами группы в качестве «писаря». Получив ее согласие, Акс-ва затем совместно с Кир-вой предложила участвовать в преступной деятельности Глуш-чу. Получив его согласие, Акс-ва затем совместно с Глуш-чем вовлекла в организованную преступную деятельность Гри-на. Получив его согласие, Акс-ва затем совместно с Гри-ном предложила участвовать в преступной деятельности Пр-ко. Таким образом, все названные лица (не только Акс-ва) осуществляли действия, направленные на организацию преступной группы: фактически, Акс-ва лишь одобряла предлагаемые вовлеченным ею лицами новые кан- 
дидатуры, т.е. лишь опосредованно осуществляла действия по организации группы. Однако суд не посчитал действия Кир-вой, Глуш-ич, Гри-на действиями организационного характера, квалифицировав их действия как соисполнительство на основании дальнейшего выполнения ими ролей «курьера», «оператора», кассира». В этой связи возникает вопрос: с какими обстоятельствами следует связывать момент возникновения организованной группы, после которого новые члены организованной группы, фактически осуществляя действия организационного характера по увеличению численности группы, не могут признаваться организаторами?

Неоднозначной является позиция, касающаяся юридической природы такого соучастника, как посредник. В имеющихся работах посредник чаще всего определяется неоднозначно, как «...лицо, при участии которого ведутся отношения между сторонами преступления» [2. С. 95]. Представляется, что появление статьи $291^{1}$ УК РФ «Посредничество во взяточничестве» не означает появления нового вида соучастника. Речь идет о точном текстуальном обозначении особого случая соучастия, в котором посредник способствует, как отмечено в тексте названной статьи, достижению либо реализации соглашения о получении и даче взятки, причем в значительном размере. Другими словами, такое лицо должно рассматриваться как пособник, который, исходя из перечня характеризующих преступную роль действий, названных в ч. 5 ст. 33 УК РФ, содействует путем предоставления информации, касающейся условий дачи и получения взятки. Судебная практика с учетом п. 15.1 Постановления Пленума Верховного Суда РФ от 15 июня 2006 г. № 14 «О судебной практике по делам о преступлениях, связанных с наркотическими средствами, психотропными, сильнодействующими и ядовитыми веществами» (с изменениями и дополнениями) признает так называемых «кассиров», «операторов» и «курьеров» как соучастников незаконного сбыта наркотических средств и их аналогов, а не как посредников.

Уголовный кодекс Российской Федерации признает соучастием умышленное совместное участие двух или более лиц в совершении умышленного преступления (ст. 33). Между тем можно встретить работы, авторы которых предлагают распространить модель соучастия и на случаи совершения неосторожных преступлений, когда выделяют наравне с таким видом участия в преступлении, как соучастие, также участие в неосторожном преступлении [10. С. 98; 11. С. 99]. Приводимые в ходе обоснования авторами справедливости такого предложения примеры позволяют сказать, что они обходят стороной тезис о том, что у лиц, причастных к совершению неосторожного преступления, нет и не может быть понимания того, что они действуют согласовано, в силу чего их позиция становится уязвимой для критики.

В уголовной теории соучастия важное место занимают положения, касающиеся эксцесса исполнителя. Чаще всего под эксцессом исполнителя понимается совершение исполнителем общественно опасных действий, выходящих за умысел других соучастников и образующих самостоятель- 
ное преступление либо придающих содеянному качественно иной характер [12. С. 8-9]. Представляется, что наиболее подробная характеристика эксцесса исполнителя дана Л.М. Прозументовым, который называет следующие случаи:

- исполнитель совершает преступление, которое вообще не охватывалось умыслом соучастников;

- исполнитель выходит за пределы умысла соучастников и совершает более тяжкое однородное преступление;

- исполнитель совершает менее тяжкое преступление, чем то, которое замышлялось соучастниками;

- исполнитель совершает наряду с задуманным преступлением совершенно иное, не охваченное умыслом соучастников преступления;

- исполнитель вместо задуманного преступления совершает это же преступление, но при квалифицирующих обстоятельствах;

- действия исполнителя, соответствующие умыслу соучастников, влекут за собой неосторожные последствия [6. С. 117-120].

Кроме того, различают количественный эксцесс, когда исполнитель по своей инициативе совершает выходящее за рамки умысла иных соучастников однородное преступление, и качественный эксцесс, который предполагает совершение исполнителем преступления, посягающего на иной основной объект, которое не охватывается умыслом соучастников [13. С. 43-47]. Анализируя данную классификацию, можно заметить, что она представляет собой сведение в группы всех случаев соучастия, названных выше.

В зависимости от того, действует ли исполнитель, допускающий эксцесс, единолично либо в группе с другими лицами, различают следующие виды эксцесса исполнителя: эксцесс непосредственного исполнителя; эксцесс исполнителя в группе либо эксцесс группы исполнителей; эксцесс посредственного исполнителя, действующего в соучастии с организатором, подстрекателем или пособником [14. С. 138-147; 15. С. 108-127].

В изученных нами уголовных делах можно найти также случаи, когда «курьер» осуществляет закладки наркотических средств в большем количестве (большем числе раз), чем было запланировано организатором. С формальной точки зрения можно говорить об эксцессе исполнителя, поскольку он совершает преступление, которое вообще не охватывалось умыслом соучастников. Однако такая предпосылка устойчивости организованной группы, как интенсивность деятельности организованной группы, проявляющаяся в преступной цели вовлечения в немедицинское потребление наркотических средств возможно большего число лиц, не позволяет рассматривать названное выше действие как эксцесс исполнителя.

В уголовно-правовой доктрине одним из дискуссионных является вопрос о так называемом неудавшемся соучастии, когда иные соучастники, помимо исполнителя, не отказываются от преступления. При этом выделяют неудавшееся подстрекательство, неудавшееся пособничество, неудавшуюся преступную деятельность организатора [16. С. 106-108]. Случаи неудавшегося соучастия, как верно отмечают отдельные авторы, юридиче- 
ская оценка которых основана на теории самостоятельной ответственности соучастников, принципиально отличаются от соучастия в неоконченном преступлении, в связи с чем ответственность лиц, которые условно именуются неудавшимися соучастниками, наступает не за организацию или подстрекательство либо пособничество, а за обычное приготовление к тому преступлению, в котором указанные лица готовились участвовать в качестве организатора, подстрекателя, пособника [17. С. 11-12]. С учетом характера незаконного сбыта наркотических средств, осуществляемого путем использования электронных и информационно-коммуникационных сетей, можно предположить возможность существования неудавшегося соучастия, когда, например, приобретатель наркотика произвел его оплату, но «курьер» добровольно отказался от дальнейшей преступной деятельности, в том числе в составе организованной группы (преступного сообщества).

В заключение работы можно сделать следующие выводы:

1. Представляется спорным мнение о необходимости исключить из ч. 3. ст. 35 УК РФ характеристику устойчивости организованной группы, поскольку именно сущностная характеристика устойчивости организованной группы позволяет отграничить эту форму соучастия от группы лиц, действующих по предварительному сговору.

2. Тенденция перерастания организованной группы, осуществляющей незаконный сбыт наркотических средств и их аналогов, в преступное сообщество требует законодательного решения вопроса об ответственности лиц за вовлечение в организованную группу новых членов.

3. Не следует рассматривать как эксцесс исполнителя случаи, когда так называемый «курьер» осуществляет закладки наркотических средств в бо́льших объемах, чем было запланировано организатором: необходимо принимать во внимание существование такой предпосылки устойчивости организованной группы, как интенсивность ее деятельности, проявляющаяся в преступной цели вовлечения в немедицинское потребление наркотических средств возможно большего число лиц.

4. Не может быть соучастия в неосторожном преступлении, поскольку у лиц, причастных к его совершению, нет и не может быть понимания того, что они действуют согласованно для достижения единой преступной цели.

\section{Лuтература}

1. Уткин В.А. Предупреждение незаконного оборота наркотических средств и психотропных веществ административно-правовыми мерами // Проблемы теории и практики пресечения незаконного оборота наркотиков (федеральный и региональный аспекты) : материалы второй межрегион. науч.-практ. конф. / под ред. В.А. Анохина, В.А. Уткина. Томск : Том. гос. ун-т, 2007. С. 38-43.

2. Алехин В.П. Соучастие в террористической деятельности. М. : Юрлитинформ, 2009. 208 c.

3. Арутюнов А.А. Соучастие в преступлении. М. : Статут, 2013. 408 с.

4. Шеслер А.В. Уголовно-правовое средства борьбы с группой преступностью. Красноярск : Сиб. юрид. ин-т МВД России. 1999. 74 с. 
5. Нестеров С.В. Формы соучастия в преступлениях против общественной безопасности : автореф. дис. ... канд. юрид. наук. М., 2016. 24 с.

6. Прозументов Л.М. Групповое преступление: вопросы теории и практики. Томск : Изд-во Том. ун-та, 2010. 164 с.

7. Зелинский А.Ф. Соучастие в преступлении: лекция. Волгоград : НИиРИО ВСШ МВД СССР, 1971.43 с.

8. Козлов А.П. Соучастие: уголовно-правовые проблемы : автореф. дис. ... д-ра юрид. наук. СПб., 2003. 39 с.

9. Дядькин Д.С. Совершенствование уголовно-правового института соучастия в преступлении : автореф. дис. ... канд. юрид. наук. М., 2002. 26 с.

10. Бабий Н.А. Соучастие в преступлении: формы, виды, ответственность. М. : Юрлитинформ, 2015. 744 с.

11. Мурашев Н.Ф. Спорные вопросы теории и практики в рамках учения о преступлении : учеб.-практ. пособие. М. : Юрлитинформ, 2014. 232 с.

12. Толстопятова Н.В. Эксцесс соучастников в уголовном праве : автореф. дис. ... канд. юрид. наук. Ростов н/Д., 2004. 27 с.

13. Капинус О.С., Ображиев К.В. Эксцесс исполнителя и иных соучастников преступления: проблемы квалификации // Уголовное право. 2018. № 2. С. 42-51.

14. Цвиренко О.Л. Исполнитель преступления как вид соучастника по уголовному праву Российской Федерации / под ред. И.Я. Козаченко. Нижневартовск : Изд-во Нижневарт. ун-та, 2006. 183 с.

15. Толстопятова Н.В. Эксцесс соучастников в уголовном праве : дис. ... канд. юрид. наук. Ростов н/Д., 2004. 192 с.

16. Виденькина Ж.В., Чернышов Д.К. О некоторых вопросах неудавшегося соучастия в преступлении // Закон и право. 2018. № 5. С. 106-109.

17. Шарапов Р.Д. Соучастие в неоконченном преступлении и «неудавшееся соучастие» // Юридическая наука и правоохранительная практика. 2018. № 1 (43). С. 7-16.

Knyazkov Aleksey S., Tomsk State University (Tomsk, Russian Federation)

COMPLICITY IN THE ILLICIT SALE OF DRUGS AND THEIR ANALOGUES, PERPETRATED VIA ELECTRONIC INFORMATION AND TELECOMMUNICATION NETWORKS

Keywords: illicit sale of drugs, criminal use of electronic information and telecommunication networks, complicity, organized group, criminal community.

\section{DOI: $10.17223 / 22253513 / 30 / 5$}

The purpose of the present study is to examine certain aspects of complicity in relation to criminal activities of those who are engaged in illicit sale of drugs and their analogues by the use of electronic or information and telecommunication networks and to study court practice in such a category of cases i.e. cases committed in complicity.

One of the objectives of the study was the consideration of complicity in the form of an organized group, since the nature of the illegal marketing in a specified way involves mainly the existence of close links between members of the group, performing different criminal acts. To achieve the above objective the author uses a systemically-structural; systematicfunctional, formal-legal, comparative-legal and sociological methods.

Public danger of illicit sale of drugs via electronic information and telecommunication networks is due to the possibility to significantly expand the scope of illegal marketing and to involve a huge number of individuals in non-medical drug usage.

This raises the need to consider a number of issues of complicity, particularly in the form of an organized group - the main supplier of drugs. 
The ambiguity of doctrinal approaches to understanding the complicity and its forms is pointed out. The approach, which combines simultaneous handling of objective and subjective criteria, reflects the nature of complicity to the fullest extent.

The author shares the view about the sustainability of an organized group as a fundamental characteristic of this form of complicity, and court practice confirms this view. The author names the indicative acts performed by the organizer of the given group and its members that are aimed at the functioning of the group and sale of drugs to particular persons.

The viewpoint on the possibility to apply the model of complicity to the cases of negligent crimes is criticized.

Possible cases of excess of the doer of an action with regard to the specified crime are considered.

Conclusions:

1. The opinion about the need to exclude the indication of the stability of an organized group from Part. 3, Article 35 of the Criminal Code, since it is this characteristic that enables us to distinguish this form of complicity from a group of persons acting together by a prior agreement seems to be a controversial one.

2. The tendency of developing of an organized group involved in an illicit sale of drugs and their analogues into the criminal community requires a legislative solution of the issue of liability of individuals for involving new members into an organized group.

3 . The excess of the doer of an action should not be viewed when a so-called "courier" carries out drugs in larger quantities than it was planned by the organizer: the existence of such a prerequisite for the sustainability of an organized group as the intensity of its activities should be taken into account.

4. There can be no complicity in negligent crimes since those involved in their commission have no understanding that they perform coordinated acts to achieve a single criminal purpose.

\section{References}

1. Utkin, V.A. (2007) Preduprezhdenie nezakonnogo oborota narkoticheskikh sredstv i psikhotropnykh veshchestv administrativno-pravovymi merami [Prevention of illegal circulation of narcotic drugs and psychoactive substances administrative and legal measures]. In: Anokhin, V.A. \& Utkin, V.A. (eds) Problemy teorii i praktiki presecheniya nezakonnogo oborota narkotikov (federal'nyy i regional'nyy aspekty) [Problems of the theory and practice of combating illicit drug trafficking (federal and regional aspects)]. Tomsk: Tomsk State University. pp. 38-43.

2. Alekhin, V.P. (2009) Souchastie v terroristicheskoy deyatel'nosti [Complicity in terrorist activities]. Moscow: Yurlitinform.

3. Arutyunov, A.A. (2013) Souchastie v prestuplenii [Complicity in the crime]. Moscow: Statut.

4. Shesler, A.V. (1999) Ugolovno-pravovoe sredstva bor'by s gruppoy prestupnost'yu [Criminal law means of dealing with a group of crime]. Krasnoyarsk: Ministry of Internal Affairs of Russia.

5. Nesterov, S.V. (2016) Formy souchastiya v prestupleniyakh protiv obshchestvennoy bezopasnosti [Forms of complicity in crimes against public safety]. Abstract of Law Cand. Diss. Moscow.

6. Prozumentov, L.M. (2010) Gruppovoe prestuplenie: voprosy teorii i praktiki [Group crime: theory and practice]. Tomsk: Tomsk State University.

7. Zelinskiy, A.F. (1971) Souchastie v prestuplenii [Crime complicity]. Volgograd: Ministry of Internal Affairs of the Russian Federation.

8. Kozlov, A.P. (2003) Souchastie: ugolovno-pravovye problemy [Complicity: criminal law problems]. Abstract of Law Dr. Diss. St. Petersburg. 
9. Dyadkin, D.S. (2002) Sovershenstvovanie ugolovno-pravovogo instituta souchastiya $v$ prestuplenii [Improvement of the criminal law institution of complicity in crime]. Abstract of Law Cand. Diss. Moscow.

10. Babiy, N.A. (2015) Souchastie v prestuplenii: formy, vidy, otvetstvennost' [Complicity in crime: forms, types, responsibility]. Moscow: Yurlitinform.

11. Murashev, N.F. (2014) Spornye voprosy teorii $i$ praktiki $v$ ramkakh ucheniya o prestup-lenii [Controversial issues of theory and practice in the framework of the doctrine of crime]. Moscow: Yurlitinform.

12. Tolstopyatova, N.V. (2004) Ekstsess souchastnikov v ugolovnom prave [Excess of accomplices in criminal law]. Abstract of Law Cand. Diss. Rostov-on-Don.

13. Kapinus, O.S. \& Obrazhiev, K.V. (2018) Ekstsess ispolnitelya i inykh souchastnikov pre-stupleniya: problemy kvalifikatsii [Excess of the performer and other accomplices of the crime: problems of qualification]. Ugolovnoe pravo. 2. pp. 42-51.

14. Tsvirenko, O.L. (2006) Ispolnitel' prestupleniya kak vid souchastnika po ugolovnomu pravu Rossiyskoy Federatsii [The perpetrator of the crime as a kind of accomplice in criminal law of the Russian Federation]. Nizhnevartovsk: Nizhnevartovsk State University.

15. Tolstopyatova, N.V. (2004) Ekstsess souchastnikov v ugolovnom prave [Excess of accomplices in criminal law]. Law Cand. Diss. Rostov-on-Don.

16. Videnkina, Zh.V. \& Chernyshov, D.K. (2018) O nekotorykh voprosakh neudavshegosya souchastiya $\mathrm{v}$ prestuplenii [On some issues of failed complicity in the crime]. Zakon $i$ pravo. 5. pp. 106-109.

17. Sharapov, R.D. (2018) Souchastie v neokonchennom prestuplenii i "neudavsheesya souchastie" [Complicity in the unfinished crime and the "failed complicity"]. Yuridicheskaya nauka i pravookhranitel'naya praktika - Legal Science and Law Enforcement Practice. 1(43). pp. 7-16. 